ORIGINAL ARTICLE

\section{A Trial of Early Antiretrovirals and Isoniazid Preventive Therapy in Africa}

\author{
The TEMPRANO ANRS 12136 Study Group**
}

\section{A BSTRACT}

\section{BACKGROUND}

In sub-Saharan Africa, the burden of human immunodeficiency virus (HIV)-associated tuberculosis is high. We conducted a trial with a 2-by-2 factorial design to assess the benefits of early antiretroviral therapy (ART), 6-month isoniazid preventive therapy (IPT), or both among HIV-infected adults with high CD4+ cell counts in Ivory Coast.

\section{METHODS}

We included participants who had HIV type 1 infection and a CD4+ count of less than 800 cells per cubic millimeter and who met no criteria for starting ART according to World Health Organization (WHO) guidelines. Participants were randomly assigned to one of four treatment groups: deferred ART (ART initiation according to WHO criteria), deferred ART plus IPT, early ART (immediate ART initiation), or early ART plus IPT. The primary end point was a composite of diseases included in the case definition of the acquired immunodeficiency syndrome (AIDS), non-AIDS-defining cancer, non-AIDS-defining invasive bacterial disease, or death from any cause at 30 months. We used Cox proportional models to compare outcomes between the deferred-ART and early-ART strategies and between the IPT and no-IPT strategies.

\section{RESULTS}

A total of 2056 patients ( $41 \%$ with a baseline CD4+ count of $\geq 500$ cells per cubic millimeter) were followed for 4757 patient-years. A total of 204 primary end-point events were observed (3.8 events per 100 person-years; 95\% confidence interval [CI], 3.3 to 4.4), including 68 in patients with a baseline CD4+ count of at least 500 cells per cubic millimeter (3.2 events per 100 person-years; $95 \%$ CI, 2.4 to 4.0 ). Tuberculosis and invasive bacterial diseases accounted for $42 \%$ and $27 \%$ of primary end-point events, respectively. The risk of death or severe HIV-related illness was lower with early ART than with deferred ART (adjusted hazard ratio, 0.56; 95\% CI, 0.41 to 0.76 ; adjusted hazard ratio among patients with a baseline CD4+ count of $\geq 500$ cells per cubic millimeter, $0.56 ; 95 \% \mathrm{CI}, 0.33$ to 0.94 ) and lower with IPT than with no IPT (adjusted hazard ratio, 0.65 ; 95\% CI, 0.48 to 0.88 ; adjusted hazard ratio among patients with a baseline CD4+ count of $\geq 500$ cells per cubic millimeter, $0.61 ; 95 \% \mathrm{CI}, 0.36$ to 1.01 ). The 30 -month probability of grade 3 or 4 adverse events did not differ significantly among the strategies.

\section{CONCLUSIONS}

In this African country, immediate ART and 6 months of IPT independently led to lower rates of severe illness than did deferred ART and no IPT, both overall and among patients with CD4+ counts of at least 500 cells per cubic millimeter. (Funded by the French National Agency for Research on AIDS and Viral Hepatitis; TEMPRANO ANRS 12136 ClinicalTrials.gov number, NCT00495651.)
The members of the writing group, who are listed in the Appendix, assume responsibility for the content and integrity of this article. Address reprint requests to Dr. Anglaret at INSERM Unité 897, Université de Bordeaux, 146 rue Léo Saignat, 33076 Bordeaux, France, or at xavier .anglaret@isped.u-bordeaux2.fr.

*A list of additional members of the TEMPRANO ANRS 12136 Study Group is provided in the Supplementary Appendix, available at NEJM.org.

This article was published on July 20, 2015, at NEJM.org.

DOI: 10.1056/NEJMoal507198 Copyright (C) 2015 Massachusetts Medical Society. 
T

HE RECOMMENDED CD4+ COUNT threshold for starting antiretroviral therapy (ART) in asymptomatic human immunodeficiency virus (HIV)-infected adults in lower-resource countries was increased from 200 cells per cubic millimeter in 2006 to 500 cells per cubic millimeter in 2013..$^{1,2}$ This change was supported by the results of two randomized, controlled trials. ${ }^{3,4}$

Meanwhile, three types of arguments have emerged to support even earlier initiation of ART. First, there is increasing documentation of inflammation in people with uncontrolled viral replication and of non-acquired immunodeficiency syndrome (AIDS)-defining noninfectious diseases as causes of death in HIV-infected persons $^{5,6}$ (with AIDS-defining diseases identified as diseases included in the Centers for Disease Control and Prevention case definition of AIDS ${ }^{7}$ ). Second, among patients living with HIV in lower-resource countries, the rates of tuberculosis and bacterial diseases are high. These infectious diseases are both common and opportunistic, meaning that their incidence is high in the general population, higher among HIV-infected patients with high CD4+ cell counts, and extremely high among patients with low CD4+ cell counts. ${ }^{8,9}$ They have consistently been shown to be major causes of death among HIV-infected patients in settings where access to diagnosis and treatment is low. ${ }^{10-16}$ These diseases triggered the question "Should we start ART earlier?" in low-income countries. ${ }^{17}$

Third, ART has been shown to be effective in reducing the risk of HIV transmission. ${ }^{3}$ This observation led to the hypothesis that recommending all HIV-infected persons to start ART irrespective of their CD4+ count might help curb the epidemic. ${ }^{18}$ This public health argument, however, is acceptable only if earlier ART leads to a favorable benefit-risk ratio at the individual level.

Here we present the results of a trial that assessed the efficacy of early ART in reducing the rate of severe illness among HIV-infected adults in Ivory Coast. Because tuberculosis was expected to be an important target for early ART in this African country, the benefit of combining isoniazid preventive therapy (IPT) with early ART was assessed in the same trial, with the use of a factorial design. In Ivory Coast, the national guidelines do not recommend the use of IPT, owing to the concern that IPT may select resistant bacilli when given to patients with undiagnosed tuberculosis. ${ }^{19,20}$ The Ministry of Health accepted its use within an experimental framework.

\section{METHODS}

\section{STUDY DESIGN AND OVERSIGHT}

The TEMPRANO ANRS 12136 trial was an unblinded, multicenter, individual-randomized, controlled, 2-by-2 factorial, 1:1 superiority trial that was conducted at nine care centers in Abidjan, the economic capital of Ivory Coast. A description of the full study design is provided in the protocol and statistical analysis plan, available with the full text of this article at NEJM.org.

The protocol was approved by the Ivory Coast National Ethics Committee for Health Research. The sponsor (the French National Agency for Research on AIDS and Viral Hepatitis [ANRS]) had no role in the conduct of the study or the interpretation of the data.

\section{PARTICIPANTS}

Patients were eligible for inclusion in the study if they were 18 years of age or older, had HIV type 1 (HIV-1) infection or dual infection with HIV-1 and HIV-2, had a CD4+ count of less than 800 cells per cubic millimeter, provided written informed consent, and met no criteria for starting ART according to the most recent World Health Organization (WHO) guidelines. The latter included the absence of active tuberculosis, as determined with the use of a clinical algorithm. ${ }^{21,22}$ No chest radiography was systematically performed before inclusion. The exclusion criteria are listed in Section 2 in the Supplementary Appendix, available at NEJM.org.

\section{RANDOMIZATION TO TRIAL GROUPS AND STRATEGIES}

A computer-generated, sequentially numbered, block randomization list, stratified according to study clinic, was drawn up and then included in a software tool that allowed access to the next available trial identification number and treatment group. Participants were randomly assigned to one of four groups: group 1 (deferred ART), in which ART was deferred until WHO criteria for starting ART were met; group 2 (deferred ART plus IPT), in which ART was deferred 
until WHO criteria for starting ART were met and a 6-month course of IPT was started 1 month after enrollment; group 3 (early ART), in which ART was started immediately; and group 4 (early ART plus IPT), in which ART was started immediately and a 6-month course of IPT was started 1 month after enrollment. We will refer to trial groups each time we show separate data for each of the four groups and refer to trial strategies whenever we show data combining patients assigned to early ART (groups 3 and 4), deferred ART (groups 1 and 2), IPT (groups 2 and 4), or no IPT (groups 1 and 3).

\section{BASELINE TESTS}

After the participants underwent randomization, plasma HIV-1 RNA was measured in all participants by means of a real-time polymerase-chainreaction assay (Generic HIV Charge Virale, Biocentric; threshold of detectability, 100 copies per milliliter), and systematic chest radiography was performed. The first 967 patients who underwent randomization also underwent an interferon-gamma release assay (IGRA) for tuberculosis (QuantiFERON-TB Gold test, Celestis). Other tests are listed in Section 2 in the Supplementary Appendix. All trial tests were performed in one reference laboratory. Tuberculin skin tests were not performed.

\section{TRIAL DRUGS}

The first-line ART regimen consisted preferably of tenofovir-emtricitabine plus efavirenz. Patients with contraindications to efavirenz received tenofovir-emtricitabine plus lopinavirritonavir, or tenofovir-emtricitabine plus zidovudine. The latter regimen was abandoned in December 2008 owing to increased side effects in the upper digestive tract. ${ }^{23}$

IPT consisted of $300 \mathrm{mg}$ of isoniazid daily, which was started 1 month after enrollment and stopped 7 months after enrollment. All the patients who were randomly assigned to groups 2 and 4 were eligible for IPT irrespective of the results on IGRA for tuberculosis. However, patients who had images suggestive of active tuberculosis on their baseline chest radiograph, those who had aminotransferase levels greater than 2.5 times the upper limit of the normal range, and those in whom clinical signs suggestive of tuberculosis developed during the first month after enrollment were not prescribed IPT.
Trimethoprim-sulfamethoxazole prophylaxis was prescribed in all patients who had a CD4+ count of less than 500 cells per cubic millimeter and no history of serious side effects from the drug. It was stopped when the CD4+ count rose above 500 cells per cubic millimeter.

Merck Sharp \& Dohme donated Stocrin (efavirenz) and Gilead Sciences donated Truvada (tenofovir-emtricitabine) for all participants in the study; these companies had no other role in the study. Nouvelle Pharmacie de Santé Publique of Ivory Coast provided all other antiretroviral drugs, with support from the U.S. President's Emergency Plan for AIDS Relief.

\section{EVOLUTION OF TRIAL PROCEDURES}

The trial started in March 2008 and ended in January 2015. During this time period, the WHO guidelines for ART changed twice., ${ }^{1,2}$ The inclusion criterion of "no WHO criteria for starting ART" and the criteria for starting ART in patients assigned to the deferred-ART strategy were thus updated over time in line with WHO guideline updates (Section 2 in the Supplementary Appendix).

\section{END POINTS}

Participants were followed for 30 months. Visits were scheduled monthly for 3 months and quarterly thereafter. CD4+ counts and plasma HIV-1 RNA levels were measured every 6 months. Clinical events were reviewed by an event-documentation committee whose members were aware of the randomization assignments; events were classified as definite, probable, or possible according to standardized criteria (Sections 3 and 4 in the Supplementary Appendix).

The primary end point was a composite of death from any cause, AIDS-defining disease, non-AIDS-defining cancer, or non-AIDS-defining invasive bacterial disease (Section 2 in the Supplementary Appendix). The main secondary end point was grade 3 or 4 illness, including all events with a grade of 3 or 4 according to the ANRS grading table (Section 5 in the Supplementary Appendix). Other secondary end points were virologic suppression, which was assessed as the percentage of patients with an undetectable viral load, and adherence to treatment, as assessed by the medication possession ratio (the number of daily doses of antiretroviral drugs dispensed by the pharmacy to each patient, di- 
vided by that patient's total follow-up time in days since the initiation of ART). ${ }^{24}$ Participants were considered to have completed IPT if they attended all six isoniazid prescription visits.

\section{STATISTICAL ANALYSIS}

We calculated that with 2076 participants enrolled, the study would have $80 \%$ power to detect a $40 \%$ lower rate of the primary end point with a new strategy (early ART or IPT) than with the corresponding reference strategy (deferred ART or no IPT), assuming a $10 \%$ rate of the primary end point in the reference strategy and with correction factors to account for a $4.2 \%$ loss to follow-up (on the basis of previous studies) and for testing for interactions (Section 2 in the Supplementary Appendix). Main analyses were performed on an intention-to-treat basis.

For each trial group and strategy, we used the Kaplan-Meier method to estimate the cumulative probability of the occurrence of an event and estimated rates by dividing the number of first events by the cumulative time at risk. Then, considering all groups together, we estimated $\mathrm{CD} 4+$-specific rates in the entire trial population by dividing the number of first events that occurred during the time that patients had CD4+ counts within a given stratum by the cumulative time at risk spent in the stratum. Follow-up data were censored when participants were lost to follow-up before their 30-month visit (Section 2 in the Supplementary Appendix).

Multivariate Cox proportional-hazards models were used to compare strategies with respect to event rates for the primary end point and its components and for the main secondary end point. Models systematically included three explanatory variables: IPT status (yes vs. no), ART status (early vs. deferred), and trial center. Hazard ratios were thus adjusted for the other strategy and the trial center. Interaction between strategies was tested. The assumption of the proportional hazards was examined.

Prespecified sensitivity analyses were performed to explore the influence of baseline CD4+ count and the robustness of the results with varying definitions of end points (Section 2 in the Supplementary Appendix). All reported $P$ values were two-sided and have not been adjusted for multiple testing. Statistical analyses were performed with the use of SAS software, version 9.3 (SAS Institute).

\section{RESULTS}

\section{BASELINE AND FOLLOW-UP CHARACTERISTICS}

Between March 18, 2008, and July 16, 2012, a total of 2076 patients were randomly assigned to treatment groups; 20 (1\%) were subsequently excluded and 2056 (99\%) were included in the analyses (Fig. 1). Participants assigned to the deferred-ART strategy were followed for 2382 person-years, and those assigned to the early-ART strategy were followed for 2375 person-years (Table 1). The rate of attendance at scheduled visits was $93 \%$ at 3 months and $86 \%$ at 30 months (Table S1 in Section 6 in the Supplementary Appendix). At study termination, 47 patients $(2 \%)$ were known to have died, and 58 (3\%) were considered to have been lost to follow-up, with no significant differences among the strategies.

\section{TRIAL INTERVENTIONS}

Among patients assigned to the deferred-ART strategy, the 30-month probability of starting ART was 63\% (Fig. S1 in Section 7 in the Supplementary Appendix). Among the 1033 patients assigned to the early-ART strategy, 911 had a viral-load measurement after 12 months, of whom $84 \%$ had an undetectable viral load, and 872 had a viral-load measurement after 24 months, of whom $83 \%$ had an undetectable viral load. Among the 391 patients assigned to deferred ART who started ART more than 12 months before the 30-month visit, 331 had a viral-load measurement after 12 months of ART, of whom $80 \%$ had an undetectable viral load. Among the 70 patients assigned to deferred ART who started ART more than 24 months before the 30-month visit, 63 had a viral-load measurement after 12 months of ART, of whom 81\% had an undetectable viral load. Of the 1030 patients assigned to the IPT strategy, 927 (90\%) actually started isoniazid, of whom $94 \%$ completed the 6-month treatment period (Table 1).

\section{EVOLUTION OF CD4+ COUNTS}

Among patients assigned to the early-ART strategy, the mean CD4+ count increased from 481 cells per cubic millimeter at baseline to 728 cells per cubic millimeter at 30 months. Among patients assigned to the deferred-ART strategy, the mean CD4+ count decreased from 472 cells per cubic millimeter at baseline to 428 cells per cubic millimeter at 12 months and then increased 


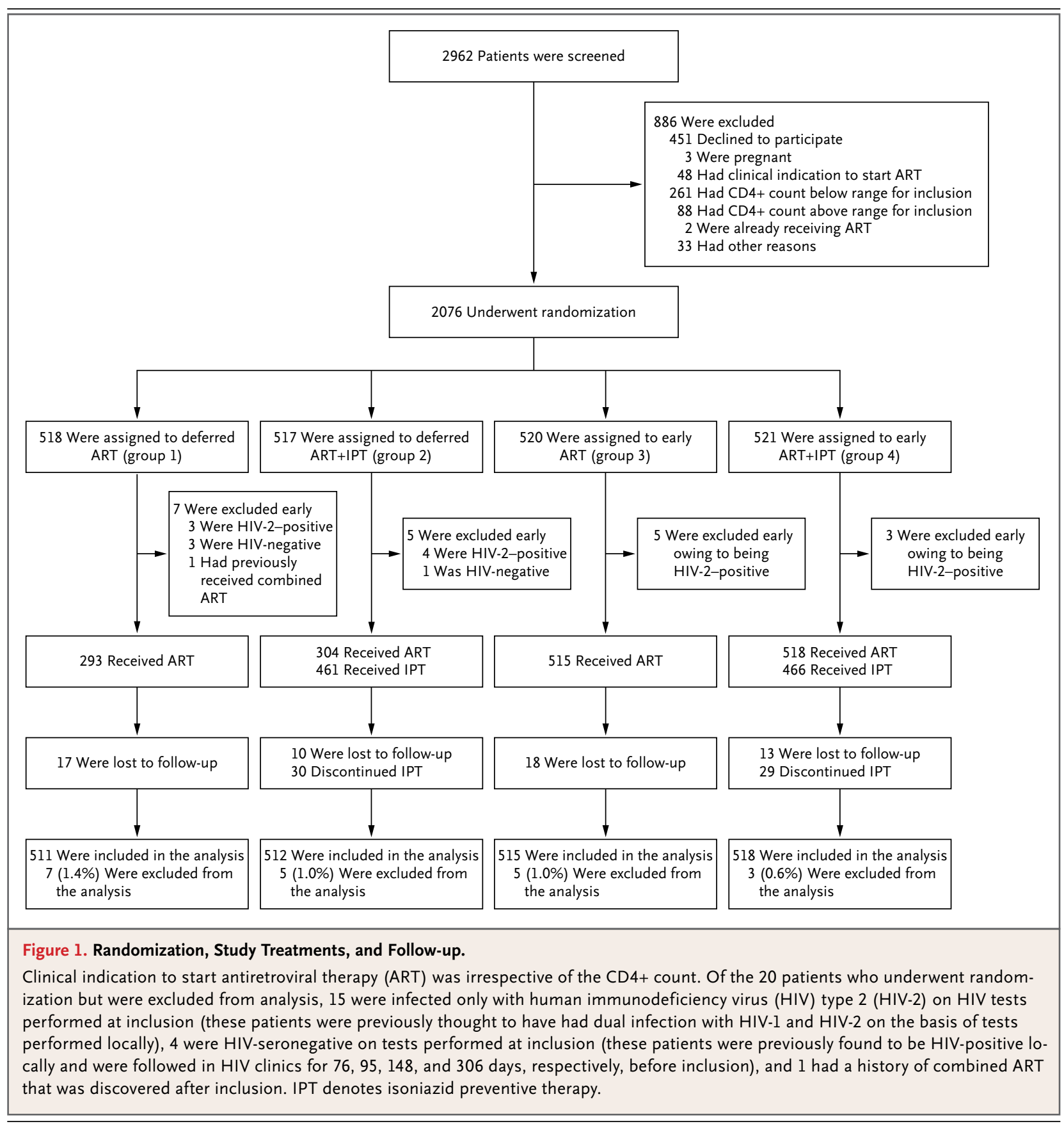

to 511 cells per cubic millimeter at 30 months (Fig. S2, S3, and S4 in Section 7 in the Supplementary Appendix). The evolution of the CD4+ count did not differ significantly between patients assigned to IPT and those assigned to no IPT. On average, patients had CD4+ counts of at least 500 cells per cubic millimeter during $51 \%$ of their follow-up time (Fig. S5 in Section 7 in the Supplementary Appendix).

\section{PRIMARY END POINT AND ITS COMPONENTS}

During follow-up, 204 primary end-point events were recorded in 175 patients. With all groups considered together, the overall rate of the primary end point was 3.8 events per 100 personyears (95\% confidence interval [CI], 3.3 to 4.4 ), and the CD4+-specific rates of the primary end point for the time during which patients had CD4+ counts of at least 500 cells per cubic mil- 


\begin{tabular}{|c|c|c|c|c|}
\hline Characteristic & $\begin{array}{c}\text { Group 1: } \\
\text { Deferred ART } \\
(\mathrm{N}=511)\end{array}$ & $\begin{array}{c}\text { Group 2: } \\
\text { Deferred ART } \\
\text { plus IPT } \\
(\mathrm{N}=512)\end{array}$ & $\begin{array}{l}\text { Group 3: } \\
\text { Early ART } \\
(\mathrm{N}=515)\end{array}$ & $\begin{array}{l}\text { Group 4: } \\
\text { Early ART } \\
\text { plus IPT } \\
(\mathrm{N}=518)\end{array}$ \\
\hline \multicolumn{5}{|l|}{ Baseline } \\
\hline Female sex — no. (\%) & $400(78)$ & $391(76)$ & 407 (79) & $416(80)$ \\
\hline \multicolumn{5}{|l|}{ Age $-y r$} \\
\hline Median & 35 & 35 & 35 & 35 \\
\hline Interquartile range & $29-41$ & $30-42$ & $30-42$ & $29-42$ \\
\hline \multicolumn{5}{|l|}{ Educational level — no. (\%) } \\
\hline Primary school or less & $275(54)$ & $270(53)$ & $282(55)$ & $287(55)$ \\
\hline Secondary school or more & $236(46)$ & $242(47)$ & $233(45)$ & $231(45)$ \\
\hline \multicolumn{5}{|l|}{ WHO clinical stage of HIV infection - no. (\%) } \\
\hline 1 & $340(67)$ & $326(64)$ & $333(65)$ & $322(62)$ \\
\hline 2 & $126(25)$ & $134(26)$ & $132(26)$ & $145(28)$ \\
\hline$\geq 3$ & $45(9)$ & $52(10)$ & $50(10)$ & $51(10)$ \\
\hline \multicolumn{5}{|l|}{ CD $4+$ count - cells $/ \mathrm{mm}^{3}$} \\
\hline Median & 460 & 459 & 467 & 466 \\
\hline Interquartile range & $359-560$ & $364-575$ & $369-584$ & $394-572$ \\
\hline \multicolumn{5}{|l|}{ CD4+ count stratum - no. (\%) } \\
\hline$\geq 500$ cells $/ \mathrm{mm}^{3}$ & $201(39)$ & $212(41)$ & $222(43)$ & $214(41)$ \\
\hline $350-499$ cells $/ \mathrm{mm}^{3}$ & $189(37)$ & $193(38)$ & $188(37)$ & $211(41)$ \\
\hline$<350$ cells $/ \mathrm{mm}^{3}$ & $121(24)$ & $107(21)$ & $105(20)$ & $93(18)$ \\
\hline \multicolumn{5}{|l|}{ Plasma HIV-1 RNA - $\log _{10}$ copies/ml } \\
\hline Median & 4.6 & 4.6 & 4.7 & 4.7 \\
\hline Interquartile range & $4.0-5.2$ & $4.0-5.3$ & $4.0-5.3$ & $4.0-5.3$ \\
\hline Dual infection with HIV-1 and HIV-2 - no. (\%) & $10(2)$ & $12(2)$ & $15(3)$ & $14(3)$ \\
\hline Creatinine clearance $<50 \mathrm{ml} / \mathrm{min}-$ no. (\%) & $6(1)$ & $9(2)$ & $4(1)$ & $9(2)$ \\
\hline Plasma alanine aminotransferase $>2.5 \times U L N-$ no. (\%) & $1(<0.5)$ & $4(1)$ & $3(1)$ & $2(<0.5)$ \\
\hline Hemoglobin $<95 \mathrm{~g} /$ liter — no. (\%) & $52(10)$ & $48(9)$ & $64(12)$ & $54(10)$ \\
\hline Positive test for hepatitis B surface antigen — no. (\%) & $42(8)$ & $48(9)$ & $49(10)$ & $54(10)$ \\
\hline Positive IGRA for tuberculosis - no./total no. (\%) $\dagger$ & $89 / 244(36)$ & $88 / 241(37)$ & $84 / 241(35)$ & $76 / 241(32)$ \\
\hline \multicolumn{5}{|l|}{ Follow-up } \\
\hline \multicolumn{5}{|l|}{ Duration of follow-up - mo } \\
\hline Median & 29.9 & 29.9 & 29.9 & 29.9 \\
\hline Interquartile range & $29.9-30.0$ & $29.9-30.0$ & $29.9-30.0$ & $29.9-30.0$ \\
\hline Lost to follow-up - no. (\%) & $17(3)$ & $10(2)$ & $18(3)$ & $13(3)$ \\
\hline Total duration of follow-up - patient-yr & 1168 & 1213 & 1177 & 1199 \\
\hline Ever started trimethoprim-sulfamethoxazole — no. (\%) & $467(91)$ & $476(93)$ & $451(88)$ & $455(88)$ \\
\hline Ever started ART — no. (\%) & $293(57)$ & $304(59)$ & $515(100)$ & $518(100)$ \\
\hline \multicolumn{5}{|l|}{ First-line ART regimen — no./total no. (\%) } \\
\hline TDF-FTC plus EFV & $205 / 293(70)$ & $216 / 304(71)$ & $362 / 515(70)$ & $354 / 518(68)$ \\
\hline TDF-FTC plus LPV/rț & $70 / 293(24)$ & $68 / 304(22)$ & $115 / 515(22)$ & $124 / 518(24)$ \\
\hline Other』 & $18 / 293(6)$ & $20 / 304(7)$ & $38 / 515(7)$ & $40 / 518(8)$ \\
\hline
\end{tabular}


Table 1. (Continued.)

\begin{tabular}{|c|c|c|c|c|}
\hline Characteristic & $\begin{array}{c}\text { Group 1: } \\
\text { Deferred ART } \\
(N=511)\end{array}$ & $\begin{array}{c}\text { Group 2: } \\
\text { Deferred ART } \\
\text { plus IPT } \\
(\mathrm{N}=512)\end{array}$ & $\begin{array}{c}\text { Group 3: } \\
\text { Early ART } \\
(\mathrm{N}=515)\end{array}$ & $\begin{array}{l}\text { Group 4: } \\
\text { Early ART } \\
\text { plus IPT } \\
(\mathrm{N}=518)\end{array}$ \\
\hline Ever started IPT — no. (\%) & 0 & $461(90)$ & 0 & $466(90)$ \\
\hline Completed 6-mo course of IPT — no./total no. (\%)\| & & $431 / 461(93)$ & & $437 / 466(94)$ \\
\hline
\end{tabular}

* None of the baseline characteristics differed significantly among the groups. ART denotes antiretroviral therapy, EFV efavirenz, FTC emtricitabine, HIV-1 human immunodeficiency virus type l, IPT isoniazid preventive therapy, LPV/r lopinavir/ritonavir, TDF tenofovir, ULN upper limit of the normal range, and WHO World Health Organization.

$\dagger$ The first 967 enrolled patients underwent an interferon-gamma release assay (IGRA) for tuberculosis (QuantiFERON-TB Gold test, Celestis).

Among the 377 patients who started ART with TDF-FTC plus LPV/r, the reason for not receiving an EFV-based regimen was dual infection with HIV-l and HIV type 2 (15 patients), a history of prevention of mother-to-child transmission with nevirapine (38), declining to use effective contraception (308), and other reasons (16).

$\int$ Other regimens were TDF-FTC-zidovudine (ZDV) (81 patients), ZDV-lamivudine (3TC)-LPV/r (25), ZDV-3TC-EFV (3), ZDV-3TC-nevirapine (3), didanosine-3TC-EFV (1), stavudine (D4T)-3TC-EFV (1), D4T-3TC-LPV/r (1), and 3TC-abacavir-LPV/r (1).

१ The reasons for not starting IPT at 1 month were the presence of signs suggestive of tuberculosis on the chest radiograph obtained at baseline (16 patients), the presence of clinical signs suggestive of tuberculosis at the 1-month visit (47), nonattendance at the 1-month visit (24), elevated aminotransferase levels at baseline (6), pregnancy (4), death before 1 month (1), and other reasons (5).

$\|$ The reasons for stopping IPT prematurely were death from an unknown cause (1 patient), discontinuation by patients for personal, nonmedical reasons (22), discontinuation by physicians because of the presence in the patient of signs or symptoms suggestive of tuberculosis (10, of whom 3 were confirmed to have tuberculosis), pregnancy (13), and the following 12 adverse events: elevated aminotransferase levels (two grade 2 events, two grade 3 events, and two grade 4 events), psychiatric side effects (two grade 2 events and two grade 3 events), and pruritus (two grade 2 events). None of the episodes of elevated aminotransferase levels led to death.

limeter, between 350 and 499 cells per cubic millimeter, and less than 350 cells per cubic millimeter were 2.8 events per 100 person-years (95\% CI, 2.1 to 3.5), 4.1 events per 100 personyears (95\% CI, 3.0 to 5.1), and 6.8 events per 100 person-years (95\% CI, 5.0 to 8.6), respectively (Fig. S6 in Section 7 in the Supplementary Appendix).

The mean $( \pm S D)$ CD4+ count at the onset of a first primary end-point event was $414 \pm 162$ cells per cubic millimeter among patients assigned to the deferred-ART strategy and $547 \pm 239$ cells per cubic millimeter among patients assigned to the early-ART strategy. The 30 -month probability of a primary end-point event was $11.4 \%$ among patients assigned to the deferred-ART strategy, $6.6 \%$ among patients assigned to the early-ART strategy, $10.7 \%$ among patients assigned to the no-IPT strategy, and $7.2 \%$ among patients assigned to the IPT strategy (Fig. S7 in Section 7 in the Supplementary Appendix). Probabilities according to treatment group are shown in Figure 2. The hazard ratio for a primary end-point event was 0.56 ( $95 \%$ CI, 0.41 to 0.76 ) with early ART as compared with deferred ART (Fig. 3) and 0.65 (95\% CI, 0.48 to 0.88 ) with IPT as compared with no IPT (Fig. 4). There was no significant interaction among the strategies $(\mathrm{P}=0.45)$. These findings were robust to adjustment for baseline
CD4+ count, the exclusion of patients enrolled before December 2009, the censoring of followup data at the time a first CD4+ count of less than 350 cells per cubic millimeter was measured, consideration of only events classified as definite, consideration of each end-point component separately, and stratification according to baseline CD4+ count, as well as in an analysis in which patients with missing data were categorized as having treatment failure and a per-protocol analysis (Fig. 3 and 4, and Table S6 in Section 6 in the Supplementary Appendix).

The primary end-point component that occurred most frequently was tuberculosis (42\%), followed by invasive bacterial diseases (27\%), death from any cause (23\%), AIDS-defining or nonAIDS-defining cancers (4\%), and other AIDS-defining diseases (3\%) Table 2). Drug-sensitivity testing was performed in 40 of the 41 patients with culture-confirmed tuberculosis: 4 had multidrug-resistant tuberculosis ( 1 had been assigned to the IPT strategy, and 3 had been assigned to the no-IPT strategy), 5 had isoniazid monoresistance ( 3 had been assigned to the IPT strategy, and 2 had been assigned to the no-IPT strategy), and 5 had another resistance profile ( 1 had been assigned to the IPT strategy, and 4 had been assigned to the no-IPT strategy). Of the 967 patients who had a serum test for tuberculosis, 597 


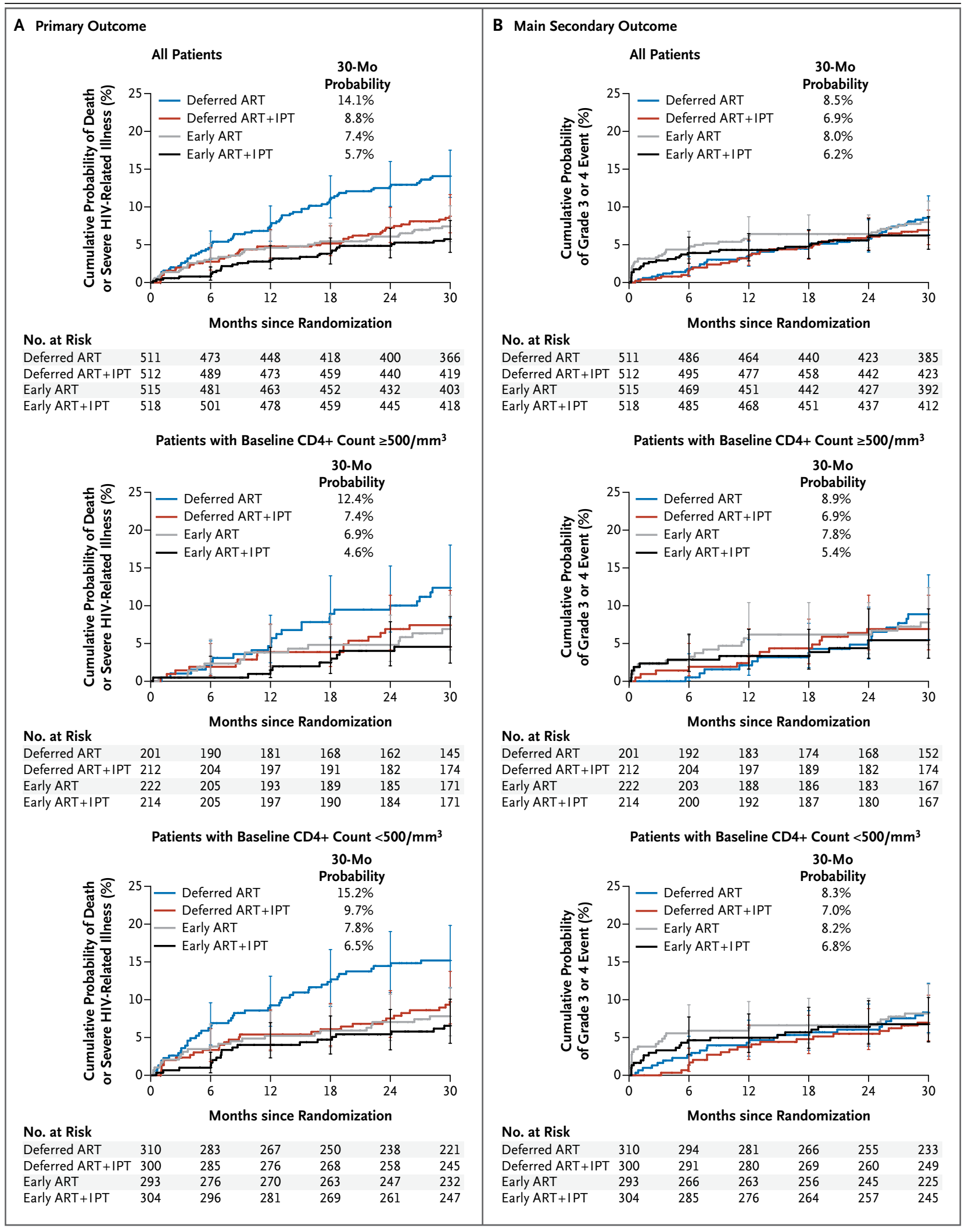


Figure 2 (facing page). Kaplan-Meier Curves of Probability of the Primary End Point and Main Secondary End Point.

The primary end point was a composite of death from any cause, AIDS-defining disease, non-AIDS-defining cancer, or non-AIDS-defining invasive bacterial disease. The main secondary end point was events of grade 3 or 4 according to the grading table for severe adverse events of the French National Agency for Research on AIDS and Viral Hepatitis. I bars represent $95 \%$ confidence intervals.

had a negative test, 337 had a positive test, and $33 \mathrm{had}$ an indeterminate test result. Of the 597 patients with a negative test, 16 went on to have tuberculosis. Of the 337 patients with a positive test, 26 went on to have tuberculosis. Among patients with a positive test, those who were assigned to IPT had significantly fewer tuberculosis events than those assigned to no IPT (adjusted hazard ratio, 0.43 ; $95 \% \mathrm{CI}, 0.19$ to 0.99 ). Among patients with a negative test, those who were assigned to IPT also had fewer tuberculosis events than those assigned to no IPT, but the difference was not significant (adjusted hazard ratio, $0.58 ; 95 \% \mathrm{CI}, 0.21$ to 1.61 ).

\section{GRADE 3 OR 4 ADVERSE EVENTS}

During follow-up, 165 grade 3 or 4 events were recorded in 144 patients (Table 2). The cumulative probability of a grade 3 or 4 event over a 30 -month period was $7.7 \%$ among patients assigned to the deferred-ART strategy, 7.1\% among patients assigned to the early-ART strategy, $8.2 \%$ among patients assigned to the no-IPT strategy, and $6.6 \%$ among patients assigned to the IPT strategy (Fig. S7 in Section 7 in the Supplementary Appendix). The risk of grade 3 or 4 events was 2.6 times as high among patients assigned to early ART as among patients assigned to deferred ART during the first 6 months and 2.1 times as low among patients assigned to early ART as among patients assigned to deferred ART thereafter. The risk of grade 3 or 4 events did not differ significantly between patients assigned to IPT and those assigned to no IPT (Fig. 4).

\section{PARTICIPANTS WITH A BASELINE CD4+ COUNT} OF AT LEAST 500 CELLS PER CUBIC MILLIMETER

A total of 849 patients had a CD4+ count of at least 500 cells per cubic millimeter at baseline.
Among patients with these baseline CD4+ counts who were assigned to the deferred-ART strategy, the cumulative 30-month probability of starting ART was $41 \%$ (Fig. S1 in Section 7 in the Supplementary Appendix); the mean CD4+ count decreased from 617 cells per cubic millimeter at baseline to 533 cells per cubic millimeter at 6 months and then remained stable. Among patients with baseline CD4+ counts of at least 500 cells per cubic millimeter who were assigned to the early-ART strategy, the mean CD4+ count increased from 617 cells per cubic millimeter at baseline to 810 cells per cubic millimeter at 30 months (Fig. S4A in Section 7 in the Supplementary Appendix). On average, patients had CD4+ counts of at least 500 cells per cubic millimeter during $77 \%$ of their follow-up time (Fig. S5 in Section 7 in the Supplementary Appendix). During follow-up, 68 primary endpoint events were recorded in 61 patients $(3.2$ events per 100 person-years; 95\% CI, 2.4 to 4.0). The mean $\mathrm{CD} 4+$ count at the onset of a first primary end-point event was $542 \pm 144$ cells per cubic millimeter among patients assigned to deferred ART and $702 \pm 287$ cells per cubic millimeter among patients assigned to early ART. The hazard ratio for a primary end-point event was 0.56 (95\% CI, 0.33 to 0.94$)$ with early ART versus deferred ART (Fig. 3) and 0.61 (95\% CI, 0.36 to 1.01) with IPT versus no IPT ( $\mathrm{P}=0.78$ for interaction) (Fig. 4).

\section{DISCUSSION}

In this study, we recruited 2056 HIV-infected adults who were not eligible to start ART at the time of enrollment according to the current WHO guidelines, in a West African country in which IPT is not recommended. Participants had baseline CD4+ counts evenly distributed on both sides of the CD4+ threshold of 500 cells per cubic millimeter. The early initiation of ART and 6 months of IPT independently resulted in a risk of severe HIV-related illness that was $44 \%$ lower and a risk of death from any cause that was 35\% lower than the risks with deferred initiation of ART and no IPT. The results were robust across alternate end-point definitions and CD4+ count strata. They were driven mainly by the efficacy of both interventions in preventing tuberculosis; the efficacy of ART in reducing invasive bacterial diseases also played a role. 


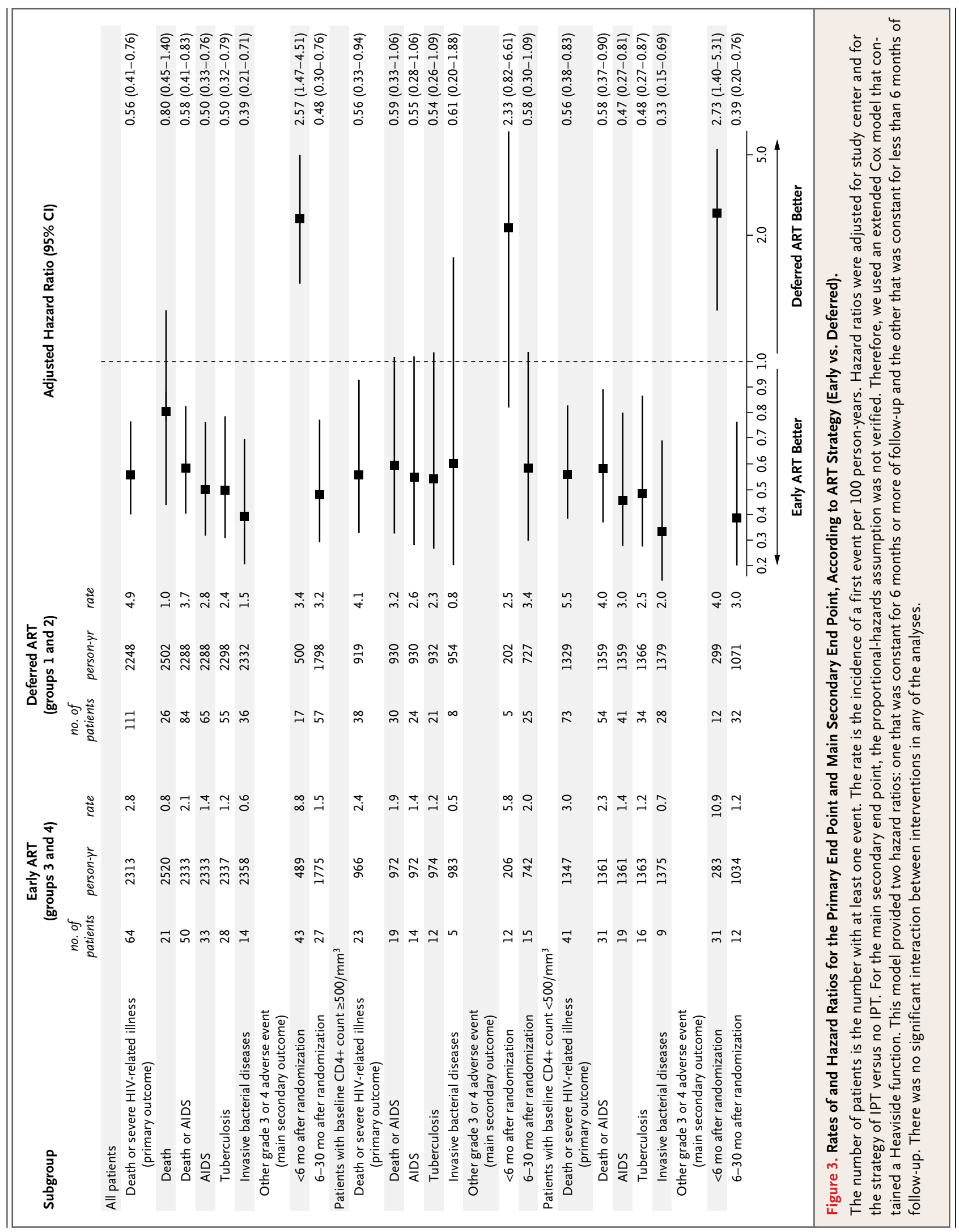




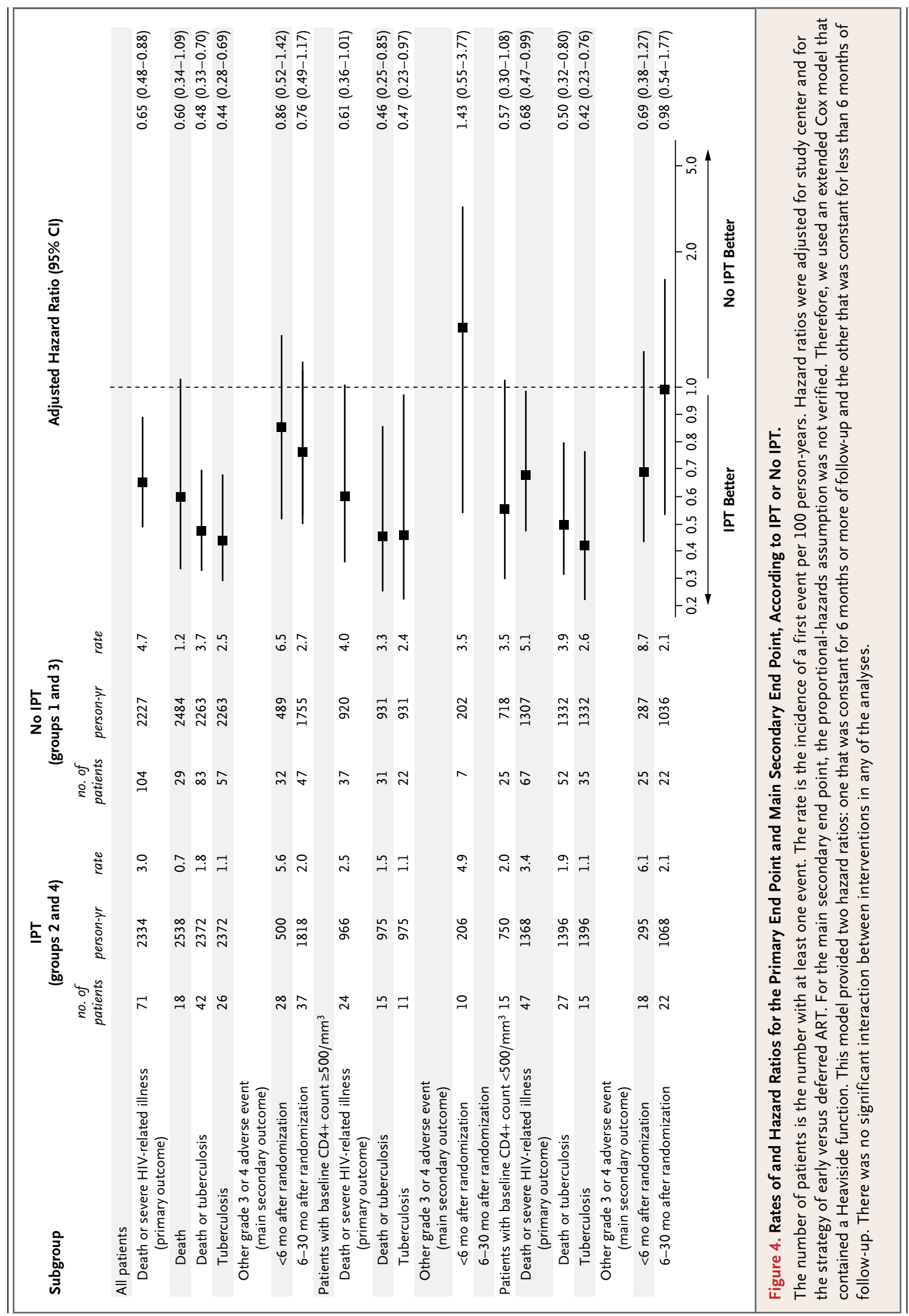

N ENGLJ MED NEJM.ORG

The New England Journal of Medicine 
Our findings suggest that starting ART before the CD4+ count falls below 500 cells per cubic millimeter may be beneficial in patients who live in countries that have a high burden of tuberculosis and bacterial diseases. The efficacy of earlier ART in decreasing the relative risk of severe illness, as estimated by hazard ratios, was similar when $\mathrm{CD} 4+$ counts were above and when they were below 500 cells per cubic millimeter, and although the absolute risk of events across CD4+ categories, as estimated by CD4+-specific rates, decreased with increasing $\mathrm{CD} 4+$ counts, the risk of events remained clinically significant during the follow-up time when patients had CD4+ counts of at least 500 cells per cubic millimeter. These findings, in patients with CD4+ counts of less than 800 cells per cubic millimeter, confirm and extend those of the HIV Prevention Trials Network 052 study, which showed similar results in patients with CD4+ counts of 350 to 550 cells per cubic millimeter. ${ }^{25}$

Despite WHO recommendations, ${ }^{22}$ many countries with a high tuberculosis burden have not adopted IPT guidelines. In those that have, the coverage remains low. ${ }^{26,27}$ Previous evidence of IPT efficacy from randomized trials was derived mostly from studies conducted before the ART era. ${ }^{22,28-31}$ Evidence for the added value of IPT in patients receiving ART was mostly from patients with $\mathrm{CD} 4+$ counts of less than 500 cells per cubic millimeter. ${ }^{32-38}$ Our data are consistent with these previous studies that showed that IPT and ART have additive efficacy with respect to the prevention of tuberculosis and that suggested that the two therapies should be given concomitantly. They also highlight for countries that are reluctant to recommend IPT that isoniazid can be prescribed safely when given early in the course of HIV disease.

Short-term adverse events were more common with earlier ART than with deferred ART and involved toxic effects that are expected with antiretroviral drugs - mainly digestive and neurologic effects. The cumulative numbers of other primary end-point components, including AIDS-defining and non-AIDS-defining cancers, and of other grade 3 or 4 events, including hematologic, renal, and hepatic events, were higher among patients assigned to the deferred-ART strategy.

Our study has several limitations. First, the frequency of events such as cancers, cardiovas- cular diseases, or bone-related toxic effects was probably underestimated, owing to limited diagnostic techniques. Second, this was an open-label study in which investigators were aware of the trial interventions. Third, during the study period, we adapted our criteria for starting ART in patients assigned to the deferred-ART strategy as WHO guidelines evolved. Therefore, the earlyART strategy was not compared with a single, unchanging reference strategy. This is both a limitation and a strength of the study, because it allowed an assessment of the efficacy of the interventions as practice changed. Our data highlight the continued benefit of starting ART earlier than at the CD4+ thresholds recommended by the WHO, even though the threshold was raised over time to 500 cells per cubic millimeter. The robustness of our results in patients with CD4+ counts of at least 500 cells per cubic millimeter suggests that the true effective treatment threshold, if there is any, is at least 800 cells per cubic millimeter.

Finally, although our findings suggest that earlier initiation of ART than is currently recommended in Ivory Coast may be beneficial, they do not answer the question of whether higher CD4+ thresholds should be used or whether ART should be recommended to all HIV-infected patients regardless of the CD4+ count. On the one hand, tuberculosis and bacterial diseases are common diseases that act as opportunistic infections in people living with HIV, and we suspect that there is no higher CD4+ threshold that could identify a sharp decrease in risk. ${ }^{39-42}$ On the other hand, patients with slow progression of HIV infection, who represent a small minority of patients, may not have the same benefitrisk ratio from earlier ART as other patients.

During the trial period, patients who started ART early and those who deferred and eventually started ART had similar rates of loss to follow-up, attendance at scheduled visits, and virologic success at 24 months. However, all the patients who were assigned to the early-ART strategy received 30 months of treatment, whereas most patients who were assigned to the deferred-ART strategy did not. We thus extended follow-up for patients assigned to the deferredART strategy who started ART during the course of the trial (i.e., within 30 months after inclusion) until they reached 30 months of treatment. Further comparison of adherence and virologic 
Table 2. Primary End-Point Events and Grade 3 or 4 Adverse Events, According to Trial Group and Strategy.

\begin{tabular}{|c|c|c|c|c|c|c|c|c|}
\hline Event & $\begin{array}{c}\text { Group 1: } \\
\text { Deferred ART }\end{array}$ & $\begin{array}{c}\text { Group 2: } \\
\text { Deferred ART } \\
\text { plus IPT }\end{array}$ & $\begin{array}{l}\text { Group 3: } \\
\text { Early ART }\end{array}$ & $\begin{array}{c}\text { Group 4: } \\
\text { Early ART } \\
\text { plus IPT } \\
\text { number }\end{array}$ & $\begin{array}{l}\text { Groups } 1 \\
\text { and 2: } \\
\text { Deferred-ART } \\
\text { Strategy } \\
\text { of events }\end{array}$ & $\begin{array}{l}\text { Groups } 3 \\
\text { and 4: } \\
\text { Early-ART } \\
\text { Strategy }\end{array}$ & $\begin{array}{l}\text { Groups } 1 \\
\text { and 3: } \\
\text { No-IPT } \\
\text { Strategy }\end{array}$ & $\begin{array}{l}\text { Groups } 2 \\
\text { and 4: } \\
\text { IPT Strategy }\end{array}$ \\
\hline \multicolumn{9}{|l|}{ Primary end-point events } \\
\hline Total & 75 & 60 & 41 & 28 & 135 & 69 & 116 & 88 \\
\hline Death* & 16 & 10 & 13 & 8 & 26 & 21 & 29 & 18 \\
\hline Tuberculosist' & 41 & 16 & 17 & 11 & 57 & 28 & 58 & 27 \\
\hline Pulmonary & 20 & 4 & 11 & 8 & 24 & 19 & 31 & 12 \\
\hline Extrapulmonary & 21 & 12 & 6 & 3 & 33 & 9 & 27 & 15 \\
\hline Invasive bacterial disease $\mathbb{\int}$ & 14 & 28 & 7 & 7 & 42 & 14 & 21 & 35 \\
\hline $\begin{array}{c}\text { AIDS-defining or non-AIDS- } \\
\text { defining cancer }\end{array}$ & 1 & 5 & 1 & 2 & 6 & 3 & 2 & 7 \\
\hline Others AIDS-defining disease & 3 & 1 & 3 & 0 & 4 & 3 & 6 & 1 \\
\hline \multicolumn{9}{|l|}{ Grade 3 or 4 adverse events $\|$} \\
\hline Total & 46 & 44 & 42 & 33 & 90 & 75 & 88 & 77 \\
\hline Hematologic & 26 & 19 & 16 & 10 & 45 & 26 & 42 & 29 \\
\hline Liver-related & 8 & 7 & 5 & 5 & 15 & 10 & 13 & 12 \\
\hline Renal & 5 & 7 & 0 & 1 & 12 & 1 & 5 & 8 \\
\hline Digestive & 0 & 2 & 8 & 9 & 2 & 17 & 8 & 11 \\
\hline Neurologic & 2 & 3 & 10 & 3 & 5 & 13 & 12 & 6 \\
\hline Cardiovascular & 2 & 4 & 1 & 2 & 6 & 3 & 3 & 6 \\
\hline Cutaneous & 1 & 0 & 2 & 1 & 1 & 3 & 3 & 1 \\
\hline Other & 2 & 2 & 0 & 2 & 4 & 2 & 2 & 4 \\
\hline
\end{tabular}

* Of the 47 deaths, 22 were considered to be of unknown cause; in the case of 25 deaths, a possible or probable cause of death was identified. Of the latter, 15 were incident events (the main criterion for diagnosing the disease appeared after the patient's enrollment in the study), and 10 were prevalent events (the main criterion for diagnosing the disease was proved to have been present at the time of enrollment). The 15 incident events that were considered to be a possible or probable cause of death were 5 events of tuberculosis, 2 events of hepatitis, and 1 event each of stroke, necrotizing fasciitis, visceral abscess, lymphoma, non-AIDS-defining cancer, cryptococcosis, renal insufficiency, and firearm injury. The 10 prevalent events that were considered to be a possible or probable cause of death were 3 events of tuberculosis, 3 events of non-AIDS-defining cancer, 2 events of renal insufficiency, and 1 event each of bacterial pneumonia and myocardiopathy.

$\uparrow$ Of the 85 episodes of tuberculosis, 44 were documented as definite ( 41 with positive cultures and 5 with histologic evidence, including 2 with positive cultures), 29 as probable, and 12 as possible.

$¥$ The 42 extrapulmonary cases included 16 cases with both pulmonary and extrapulmonary sites. Documented extrapulmonary disorders were deep lymphadenopathy (16 cases), peripheral lymphadenopathy (9), pleural effusion (8), osteomyelitis (4), miliary disease (2), meningitis (1), pericarditis (1), esophageal ulceration (1), mammary gland infection (1), and pancytopenia (1); several disorders could occur in the same patient.

$\int$ Of the 56 episodes of invasive bacterial diseases, 30 were documented as definite and 26 as probable. The 56 episodes of invasive bacterial diseases were 23 episodes of pneumonia, 12 of isolated bacteremia, 9 of pyelonephritis, 4 of typhoid fever, 2 of prostatitis, 2 of necrotizing fasciitis, 2 of enteritis with bacteremia, 1 of visceral abscess, and 1 of septic shock (for details according to trial group and strategy, see Table S2 in Section 6 in the Supplementary Appendix). Clinically significant bacteria were isolated in 30 episodes, including 18 from blood cultures, 3 from blood and urine cultures, 1 from blood and stool cultures, and 8 from urine cultures. Pathogens were Escherichia coli (15 episodes), non-Typhi salmonella (6), Salmonella enterica serovar Typhi (4), Klebsiella pneumoniae (2), Streptococcus pneumoniae (1), citrobacter species (1), and acinetobacter species (1).

9 AIDS-defining diseases were identified as diseases included in the Centers for Disease Control and Prevention case definition of AIDS. ${ }^{7}$ Details on the specific disease events are provided in Table S2 in Section 6 in the Supplementary Appendix.

$\|$ Adverse events were categorized according to the grading table for severe adverse events of the French National Agency for Research on AIDS and Viral Hepatitis. Details on the specific events are provided in Table S3 in Section 6 in the Supplementary Appendix.

The New England Journal of Medicine 
outcomes over a 30-month period of effective treatment will provide additional insights.

In conclusion, our findings suggest that ART has a favorable benefit-risk ratio in patients before the $\mathrm{CD} 4+$ count reaches the current treatment threshold of 500 cells per cubic millimeter; we found that 6 months of IPT combined with early ART led to improved outcomes and that the spectrum of diseases for which early ART has a protective effect includes not only tuberculosis but also invasive bacterial diseases. Our data suggest that in low-resource settings, ART provides substantial clinical benefits in patients who have higher CD4+ counts at the time of initiation than those previously recommended for the initiation of ART.

Presented in part at the 17th Conference on Retroviruses and Opportunistic Infections, Seattle, February 23-26, 2015.

Supported by grants (ANRS 12136, ANRS 12224, and ANRS 12253) from the French National Agency for Research on AIDS and Viral Hepatitis.

Disclosure forms provided by the authors are available with the full text of this article.

We thank all the patients who participated in this trial. and the members of the independent data and safety monitoring board: Brigitte Autran, François-Xavier Blanc, Dominique Costagliola (chair), Ogobara Doumbo, Sinata Koulla-Shiro, Souleymane Mboup, and Yazdan Yazdanpanah. Additional acknowledgments are included in the Supplementary Appendix.

\section{APPENDIX}

The members of the writing group are as follows: Christine Danel, Ph.D., Raoul Moh, Ph.D., Delphine Gabillard, M.Sc., Anani Badje, M.P.H., Jérôme Le Carrou, Ph.D., Timothée Ouassa, Ph.D., Eric Ouattara, Ph.D., Amani Anzian, M.D., Jean-Baptiste Ntakpé, M.P.H., Albert Minga, Ph.D., Gérard M. Kouame, M.P.H., Franck Bouhoussou, M.Sc., Arlette Emieme, M.D., Antoine Kouamé, M.Sc., André Inwoley, Ph.D., Thomas-d'Aquin Toni, Ph.D., Hugues Ahiboh, Ph.D., Mathieu Kabran, M.Sc., Cyprien Rabe, M.D., Baba Sidibé, M.D., Gustave Nzunetu, M.D., Romuald Konan, M.Sc., Joachim Gnokoro, M.D., Patrice Gouesse, M.D., Eugène Messou, Ph.D., Lambert Dohoun, M.D., Synali Kamagate, M.D., Abo Yao, M.P.H., Solange Amon, M.D., Amadou-Barenson Kouame, M.D., Aboli Koua, M.D., Emmanuel Kouamé, M.D., Yao Ndri, M.D. (deceased), Olivier Ba-Gomis, M.D., Marcelle Daligou, M.D., Simplice Ackoundzé, M.D., Denise Hawerlander, M.D., Alex Ani, M.D., Fassery Dembélé, M.D., Fatoumata Koné, M.D., Calixte Guéhi, M.P.H., Constance Kanga, M.D., Serge Koule, M.D., Jonas Séri, M.D., Mykayila Oyebi, M.D., Nathalie Mbakop, M.D., Olewole Makaila, M.D., Carole Babatunde, M.D., Nathanael Babatounde, M.D., Gisèle Bleoué, M.D., Mireille Tchoutedjem, M.D., Alain-Claude Kouadio, M.D., Ghislaine Sena, M.D., Sahinou-Yediga Yededji, M.D., Rodrigue Assi, M.D., Alima Bakayoko, M.D., Alassane Mahassadi, M.P.H., Alain Attia, Ph.D., Armel Oussou, M.D., Max Mobio, M.D., Doféré Bamba, M.D., Mesmin Koman, M.D., Apollinaire Horo, M.D., Nina Deschamps, M.P.H., Henri Chenal, M.D., Madeleine Sassan-Morokro, M.P.H., Seidou Konate, M.D., Kakou Aka, M.D., Eba Aoussi, M.D., Valérie Journot, Ph.D., Célestin Nchot, M.Sc., Sophie Karcher, M.Sc., Marie-Laure Chaix, Ph.D., Christine Rouzioux, Ph.D., Papa-Salif Sow, Ph.D., Christian Perronne, Ph.D., Pierre-Marie Girard, Ph.D., Hervé Menan, Ph.D., Emmanuel Bissagnene, M.D., Auguste Kadio, M.D., Virginie Ettiegne-Traore, M.D., Corinne Moh-Semdé, M.Sc., Abo Kouame, M.D., Jean-Marie Massumbuko, M.D., Geneviève Chêne, Ph.D., Mireille Dosso, Ph.D., Serge K. Domoua, M.D., Thérèse N’Dri-Yoman, M.D., Roger Salamon, Ph.D., Serge P. Eholié, M.D., M.P.H., and Xavier Anglaret, Ph.D.

The affiliations of the members of the writing group are as follows: INSERM Unité 897, Université de Bordeaux, Talence (C.D., R.M., D.G., A. Badje, J.L., E.O., J.-B.N., A. Minga, G.M.K., E.M., C.G., V.J., S. Karcher, G.C., R.S., S.P.E., X.A.), Laboratoire de Virologie, Centre Hospitalier Universitaire (CHU) Saint Louis (M.-L.C.), Laboratoire de Virologie, CHU Necker (C. Rouzioux), and Service des Maladies Infectieuses et Tropicales, CHU Saint Antoine (P.-M.G.), Paris, and CHU Raymond Poincaré, Garches (C.P.) — all in France; Programme PAC-CI, Agence Nationale de Recherches sur le SIDA research site (C.D., R.M., D.G., A. Badje, J.L., T.O., E.O., A. Anzian, A. Minga, F.B., A.E., A. Kouamé, A.I., T.-T., H.A., M. Kabran, R.K., L.D., A.Y., N.D., C.N., S. Karcher, H.M., T.N.-Y., R.S., S.P.E., X.A.), Centre de Diagnostic et de Recherches sur le SIDA (R.M., T.O., A.E., A.I., T.-T., H.A., M. Kabran, H.M.), Service des Maladies Infectieuses et Tropicales (C. Rabe, B.S., G.N., K.A., E.A., E.B., A. Kadio, S.P.E.), Service de Pneumologie (R.A., A. Bakayoko, S.K.D.), Service d'Otorhinolaryngologie (M.M.), Service d'Ophtalmologie (D.B.), and Service de Gynécologie (M. Koman), CHU Treichville, Centre Médical de Suivi des Donneurs de Sang (A. Minga, L.D., S. Kamagate, A.Y., S. Konate), Centre Intégré de Recherches Biocliniques d'Abidjan (O.B.-G., M. Daligou, S. Ackoundzé, D.H., H.C.), Unité de Soins Ambulatoire et de Conseil (A. Ani, F.D., F.K., C.G., C.K., S. Koule, J.S.), Centre La Pierre Angulaire (A.-C.K., G.S., S.-Y.Y., M.S.-M.), Centre de Prise en Charge et de Formation (A. Anzian, J.G., P.G., E.M., C.M.-S.), Service de Gastro-entéro-hépatologie (A. Mahassadi, A. Attia, T.N.-Y.), and Service de Gynécologie Obstétrique, CHU de Yopougon (A.H.), Hôpital Général d'Abobo Nord (S. Amon, A.-B.K., A. Koua, E.K., Y.N.), Formation Sanitaire Urbaine Communautaire d'Anonkoua Kouté (M.O., N.M., O.M.), Hôpital El Rapha (C.B., N.B., G.B., M.T.), Programme National de Lutte contre le SIDA, Ministère de la Santé et de la Lutte contre le VIH/SIDA (V.E.-T., A. Kouame), Ensemble pour une Solidarité Thérapeutique Hospitalière en Réseau (J.-M.M.), and Institut Pasteur de Côte d'Ivoire (M. Dosso), Abidjan, and Service de Dermatologie du CHU de Bouaké, Bouaké (A.O.) — all in Ivory Coast; and Service des Maladies Infectieuses et Tropicales, CHU Fann, Dakar, Sénégal (P.-S.S.).

Drs. Danel and Moh and Drs. Eholié and Anglaret contributed equally to this article.

\section{REFERENCES}

1. Antiretroviral therapy for HIV infection in adults and adolescents: recommendations for a public health approach. 2010 revision. Geneva: World Health Organization (http://www.who.int/hiv/pub/ arv/adult2010/en).

2. Consolidated guidelines on the use of antiretroviral drugs for treating and pre- venting HIV infection. Recommendations for a public health approach. Geneva: World Health Organization (http://www .who.int/hiv/pub/guidelines/arv2013/en).

3. Cohen MS, Chen YQ, McCauley M, et al. Prevention of HIV-1 infection with early antiretroviral therapy. N Engl J Med 2011;365:493-505.
4. Severe P, Juste MA, Ambroise A, et al. Early versus standard antiretroviral therapy for HIV-infected adults in Haiti. N Engl J Med 2010;363:257-65.

5. Emery S, Neuhaus JA, Phillips AN, et al. Major clinical outcomes in antiretroviral therapy (ART)-naive participants and in those not receiving ART at baseline in 
the SMART study. J Infect Dis 2008;197: 1133-44.

6. Boulware DR, Hullsiek KH, Puronen $\mathrm{CE}$, et al. Higher levels of CRP, D-dimer, IL-6, and hyaluronic acid before initiation of antiretroviral therapy (ART) are associated with increased risk of AIDS or death. J Infect Dis 2011;203:1637-46.

7. 1993 Revised classification system for HIV infection and expanded surveillance case definition for AIDS among adolescents and adults. MMWR Recomm Rep 1992;41(RR-17):1-19.

8. Hirschtick RE, Glassroth J, Jordan MC, et al. Bacterial pneumonia in persons infected with the human immunodeficiency virus. N Engl J Med 1995;333:845-51.

9. Anglaret X, Minga A, Gabillard D, et al. AIDS and non-AIDS morbidity and mortality across the spectrum of CD4 cell counts in HIV-infected adults before starting antiretroviral therapy in Cote d'Ivoire. Clin Infect Dis 2012;54:714-23.

10. Lucas SB, Hounnou A, Peacock C, et al. The mortality and pathology of HIV infection in a west African city. AIDS 1993;7:1569-79.

11. Rana FS, Hawken MP, Mwachari C, et al. Autopsy study of HIV-1-positive and HIV-1-negative adult medical patients in Nairobi, Kenya. J Acquir Immune Defic Syndr 2000;24:23-9.

12. Wong EB, Omar T, Setlhako GJ, et al. Causes of death on antiretroviral therapy: a post-mortem study from South Africa. PLoS One 2012;7(10):e47542.

13. Cox JA, Lukande RL, Nelson AM, et al. An autopsy study describing causes of death and comparing clinico-pathological findings among hospitalized patients in Kampala, Uganda. PLoS One 2012;7(3): e33685.

14. Martinson NA, Karstaedt A, Venter WD, et al. Causes of death in hospitalized adults with a premortem diagnosis of tuberculosis: an autopsy study. AIDS 2007; 21:2043-50.

15. Corbett EL, Churchyard GJ, Charalambos S, et al. Morbidity and mortality in South African gold miners: impact of untreated disease due to human immunodeficiency virus. Clin Infect Dis 2002;34 1251-8.

16. Ansari NA, Kombe AH, Kenyon TA, et al. Pathology and causes of death in a group of 128 predominantly HIV-positive patients in Botswana, 1997-1998. Int J Tuberc Lung Dis 2002;6:55-63.

17. Suthar AB, Lawn SD, del Amo J, et al. Antiretroviral therapy for prevention of tuberculosis in adults with HIV: a systematic review and meta-analysis. PLoS Med 2012;9(7):e1001270.

18. Granich RM, Gilks CF, Dye C, De Cock KM, Williams BG. Universal voluntary HIV testing with immediate antiretroviral therapy as a strategy for elimination of HIV transmission: a mathematical model. Lancet 2009;373:48-57.
19. Kufa T, Mngomezulu V, Charalambous $\mathrm{S}$, et al. Undiagnosed tuberculosis among HIV clinic attendees: association with antiretroviral therapy and implications for intensified case finding, isoniazid preventive therapy, and infection control. J Acquir Immune Defic Syndr 2012; 60(2):e22-e28.

20. Lester R, Hamilton R, Charalambous $\mathrm{S}$, et al. Barriers to implementation of isoniazid preventive therapy in HIV clinics: a qualitative study. AIDS 2010;24:Suppl 5: S45-S48.

21. Getahun H, Kittikraisak W, Heilig $\mathrm{CM}$, et al. Development of a standardized screening rule for tuberculosis in people living with HIV in resource-constrained settings: individual participant data meta-analysis of observational studies. PLoS Med 2011;8(1):e1000391.

22. Guidelines for intensified tuberculosis case finding and isoniazid preventive therapy for people living with HIV in resource constrained setting. Geneva: World Health Organization (http:/l whqlibdoc.who.int/publications/2011/ 9789241500708_eng.pdf).

23. Ouattara E, Danel C, Moh R, et al. Early upper digestive tract side effects of zidovudine with tenofovir plus emtricitabine in West African adults with high CD4 counts. J Int AIDS Soc 2013;16: 18059.

24. Messou E, Chaix ML, Gabillard D, et al. Association between medication possession ratio, virologic failure and drug resistance in HIV-1-infected adults on antiretroviral therapy in Côte d'Ivoire. J Acquir Immune Defic Syndr 2011;56:35664.

25. Grinsztejn B, Hosseinipour MC, Ribaudo HJ, et al. Effects of early versus delayed initiation of antiretroviral treatment on clinical outcomes of HIV-1 infection: results from the phase 3 HPTN 052 randomised controlled trial. Lancet Infect Dis 2014;14:281-90.

26. Gupta S, Granich R, Date A, et al. Review of policy and status of implementation of collaborative HIV-TB activities in 23 high-burden countries. Int J Tuberc Lung Dis 2014;18:1149-58.

27. Getahun H, Granich R, Sculier D, et al. Implementation of isoniazid preventive therapy for people living with HIV worldwide: barriers and solutions. AIDS 2010;24:Suppl 5:S57-S65.

28. Whalen CC, Johnson JL, Okwera A, et al. A trial of three regimens to prevent tuberculosis in Ugandan adults infected with the human immunodeficiency virus. N Engl J Med 1997;337:801-8.

29. Mwinga A, Hosp M, Godfrey-Faussett $\mathrm{P}$, et al. Twice weekly tuberculosis preventive therapy in HIV infection in Zambia. AIDS 1998;12:2447-57.

30. Pape JW, Jean SS, Ho JL, Hafner A, Johnson WD Jr. Effect of isoniazid prophylaxis on incidence of active tuberculo- sis and progression of HIV infection. Lancet 1993;342:268-72.

31. Perriëns JH, St Louis ME, Mukadi YB, et al. Pulmonary tuberculosis in HIV-infected patients in Zaire - a controlled trial of treatment for either 6 or 12 months. N Engl J Med 1995;332:779-84.

32. Samandari T, Agizew TB, Nyirenda S, et al. 6-month versus 36-month isoniazid preventive treatment for tuberculosis in adults with HIV infection in Botswana: a randomised, double-blind, placebo-controlled trial. Lancet 2011;377:1588-98.

33. Charalambous $S$, Grant $A D$, Innes $C$, et al. Association of isoniazid preventive therapy with lower early mortality in individuals on antiretroviral therapy in a workplace programme. AIDS 2010;24: Suppl 5:S5-S13.

34. Rangaka MX, Wilkinson RJ, Boulle A, et al. Isoniazid plus antiretroviral therapy to prevent tuberculosis: a randomised double-blind, placebo-controlled trial. Lancet 2014;384:682-90.

35. Briggs MA, Emerson C, Modi S, Taylor NK, Date A. Use of isoniazid preventive therapy for tuberculosis prophylaxis among people living with HIV/AIDS: a review of the literature. J Acquir Immune Defic Syndr 2015;68:Suppl 3:S297-S305.

36. Yirdaw KD, Jerene D, Gashu Z, et al. Beneficial effect of isoniazid preventive therapy and antiretroviral therapy on the incidence of tuberculosis in people living with HIV in Ethiopia. PLoS One 2014;9(8): e104557.

37. Golub JE, Pronyk P, Mohapi L, et al. Isoniazid preventive therapy, HAART and tuberculosis risk in HIV-infected adults in South Africa: a prospective cohort. AIDS 2009;23:631-6.

38. Durovni B, Saraceni V, Moulton LH, et al. Effect of improved tuberculosis screening and isoniazid preventive therapy on incidence of tuberculosis and death in patients with HIV in clinics in Rio de Janeiro, Brazil: a stepped wedge, clusterrandomised trial. Lancet Infect Dis 2013; 13:852-8.

39. Kufa T, Mabuto T, Muchiri E, et al. Incidence of HIV-associated tuberculosis among individuals taking combination antiretroviral therapy: a systematic review and meta-analysis. PLoS One 2014;9(11): e111209.

40. Martinson NA, Barnes GL, Moulton $\mathrm{LH}$, et al. New regimens to prevent tuberculosis in adults with HIV infection. N Engl J Med 2011;365:11-20.

41. Lawn SD, Myer L, Edwards D, Bekker LG, Wood R. Short-term and long-term risk of tuberculosis associated with $\mathrm{CD} 4$ cell recovery during antiretroviral therapy in South Africa. AIDS 2009;23:1717-25. 42. Williams BG, Hargrove JW, Humphrey JH. The benefits of early treatment for HIV. AIDS 2010;24:1790-1.

Coppright (๑ 2015 Massachusetts Medical Society. 